\title{
ANÁLISE DAS CONFIGURAÇÕES INTERORGANIZACIONAIS NA PECUÁRIA DE CORTE GAÚCHA ${ }^{1}$
}

\author{
ANALYSIS OF THE INTERORGANIZACIONAIS SETTINGS IN CATTLE \\ GAÚCHA
}

\author{
Guilherme Cunha Malafaia ${ }^{2}$ \\ Denise Barros Azevedo ${ }^{3}$ \\ Maria Emilia Kamargo ${ }^{4}$
}

RESUMO: As mudanças no cenário competitivo mundial têm dificultado a sobrevivência das empresas, obrigando às mesmas a estabelecerem relações cooperativas necessárias à sua manutenção e sobrevivência nos mercados. A partir de tais pressupostos, o presente artigo tem como objetivo analisar os relacionamentos interorganizacionais encontrados na bovinocultura de corte do Rio Grande do Sul (RS) e seus efeitos sobre a competitividade. Inicialmente este artigo apresenta uma discussão teórica sobre a contextualização, a governança, as estratégias e a competitividade dos relacionamentos interorganizacionais. Num segundo momento esses relacionamentos são caracterizados e analisados na bovinocultura de corte no RS. Para tanto, realizaram-se entrevistas em profundidade com experts do referido setor. Os resultados apontaram para uma situação onde as relações na bovinocultura de corte gaúcha que possuem uma certa coordenação tornam-se capazes de desenvolver estratégias coletivas, gerando resultados mais atrativos aos agentes.

PALAVRAS-CHAVE: relacionamentos interorganizacionais, competitividade sistêmica, bovinocultura de corte.

\begin{abstract}
The changes in competitive scene world have made it difficult the survival of the companies, compelling to the same ones to establish necessary cooperative relations to its maintenance and survival in the markets. From such estimated, the present article has as objective to analyze the joined interorganizacional relationships in the beef cattle of Rio Grande Sul (RS) and its effect on the competitiveness. Initially this article presents a theoretical discussion on the panoramic, the governance, the strategies and the competitiveness of the interorganizacional relationships. At as a moment these relationships are characterized and analyzed in the beef cattle in the RS. For in such a way, interviews in depth with experts of the related sector had been become fulfilled. The results had pointed with respect to a situation where the relations in the gaucho beef cattle that they possess a certain coordination become capable to develop collective strategies, generating resulted more attractive the agents.
\end{abstract}

KEY WORDS: interorganization relationship, systemic competitiveness, beef cattle.

\footnotetext{
${ }^{1}$ Artigo Recebido em 18.05.2009. Revisado por pares em 25.05.2011. Recomendado em 25.07.2011 por Leomar dos Santos Editor. Publicado em 15.09.2011.

Organização Responsável pelo periódico: Universidade regional de Blumenau - FURB - www.furb.br/rn
}

\footnotetext{
${ }^{2}$ Universidade Caxias do Sul - UCS - gcmalafa@ucs.br

${ }^{3}$ Universidade Anhanguera- UNIDERP - deniazevedo@ hotmail.com

${ }^{4}$ Universidade Federal do Rio Grande Do Sul - UFRGS - kamargo@terra.com.br
} 


\section{INTRODUÇÃO}

A crescente fragilização das empresas face ao processo de globalização, bem como as rápidas mudanças tecnológicas, faz com que novas formas de gestão se incorporem no mundo dos negócios. O estabelecimento de relações interorganizacionais, onde empresas buscam concentrar-se em suas competências centrais, transferindo a terceiros as demais atividades não centrais, estão cada vez mais ganhando importância no cenário dos negócios (Sterns \& Peterson 2001).

As mudanças no cenário competitivo mundial têm dificultado a sobrevivência das empresas, obrigando as mesmas a estabelecerem relações cooperativas para obter os fatores de produção necessários à sua manutenção e sobrevivência nos mercados. Nesse contexto, percebe-se uma mudança de foco em termos de gestão, onde novas formas emergem em detrimento de outras. A visão isolada da unidade produtiva competitiva perde espaço para uma visão mais abrangente de grupos de empresas competitivas. Esses grupos de empresas podem ser, diferentemente, denominados de Cadeias, Clusters, Redes, Alianças ou Corporações Virtuais (Pedrozo \& Hansen, 2001). Percebe-se, dessa forma, que os relacionamentos interorganizacionais abrem um enorme espaço para avançar-se em estudos sobre a abordagem sistêmica e interdisciplinar.

No caso dos agronegócios existe um conjunto de especificidades que resultam na definição de um espaço sistêmico de análise da cadeia produtiva agroindustrial. Em grandes linhas, pode-se afirmar que a falta de entendimento do conceito de cadeia produtiva não permite sintonizar as organizações no seu ambiente competitivo, como ocorre com a bovinocultura de corte. Observa-se que este setor vem enfrentando constantes dificuldades econômicas, culturais e de norteamento do setor como um todo, de forma mais sistêmica (MALAFAIA et al., 2003). Neste sentido, o conhecimento da realidade estrutural e dos fatores que condicionam a governança, a competitividade e as estratégias, assume papel decisivo no encadeamento de ações específicas para exploração da bovinocultura.

Sendo assim, buscando entender a dinâmica do setor da carne bovina no Estado do Rio Grande do Sul (RS), o presente trabalho tem como objetivo analisar os relacionamentos interorganizacionais encontrados no mesmo e seus efeitos sobre a competitividade deste arranjo produtivo.

\section{REVISÃO DA LITERATURA}

\subsection{CONTEXTUALIZAÇÃO, GOVERNANÇA, ESTRATÉGIAS E COMPETITIVIDADE DOS RELACIONAMENTOS INTERORGANIZACIONAIS}

A articulação progressiva entre as várias fases do processo de produção envolvendo desde os insumos básicos, a produção, a distribuição, a comercialização e a colocação do produto final junto ao consumidor, constituindo elos de uma corrente, pode ser entendida por cadeia produtiva (MALAFAIA et al., 2003). O conceito de cadeia produtiva tem origem no conceito de Filière da escola francesa de economia industrial. Segundo Morvan (1984), para ser considerada uma cadeia produtiva, alguns elementos devem estar implicitamente 
relacionados a essa visão. Sendo assim, a cadeia produtiva pode ser considerada como sendo uma seqüência de operações que determinam a produção de bens, cujas inter-relações são largamente influenciadas pelas possibilidades tecnológicas, definidas pelas estratégias dos elos, e governadas pelas forças hierárquicas da cadeia. De acordo com Batalha (1997), o encadeamento das operações de uma cadeia produtiva ocorre sempre de jusante para montante, em outras palavras, do produto final no sentido da matéria-prima de base. Na visão de Ferreira (2003), a análise de cadeias produtivas pode servir como um mecanismo de descrição técnico-produtivo, em que as operações são descritas na seqüência na qual ocorrem, analisando-se o fluxo tecnológico. Pode-se ainda entender, através desse conceito, a estratégia individual da firma, bem como suas inter-relações com os demais elos da cadeia. Neves e Jank (1994), consideram uma cadeia de produção agroalimentar como sendo constituída pelo segmento de produção agropecuária; o segmento de transformação das matérias-primas; e o segmento de distribuição dos produtos agroalimentares. Para Zilbersztanjn (2000), a cadeia de produção poderá ter um recorte dentro de um universo maior de um sistema. Dessa forma, dependendo dos objetivos do estudo, poderão ser ou não incluídos outros segmentos à montante da produção primária, sendo que o importante é estudar aqueles que de fato são determinantes da analise principal. Sendo assim, o conceito de cadeias, segundo Batalha (2001), pode ser situado no espaço analítico delimitado pelos contornos externos da cadeia produtiva, buscando identificar eventuais disfunções que comprometam o funcionamento eficiente da mesma, bem como ser situado como ferramenta de gestão nas organizações.

Um enfoque para a análise da formação de cadeias produtivas envolve as questões de poder. Essa dimensão surge como prioritária em abordagens como a de Gereffi $(1994,1998)$ ao discutir a formação de cadeias produtivas globais. A idéia central é a de que as cadeias de produção têm estruturas de comando (governance), em que uma ou mais empresas coordenam e controlam atividades econômicas geograficamente dispersas. A racionalidade econômica na cadeia produtiva decorre do fato de que a(s) empresa(s) que comanda $(\mathrm{m})$ a cadeia procura $(\mathrm{m})$ dominar as atividades que são estratégicas e que agregam mais valor. Por outro lado, com a governança as empresas podem se organizar em relações horizontais, na qual há uma simetria de poder, com o desenvolvimento de acordos de interesse mútuo estabelecendo alianças estratégicas, nas quais há o compartilhamento de informações e de recursos para atingir objetivos de interesse comum.

Gereffi (1994) propõe a existência de dois tipos de cadeias produtivas globais: aquelas que são comandadas por produtores (producer-driven commodity chains) e as lideradas pelos compradores (buyer-driven commodity chains). Gereffi (1994) observa que as cadeias globais de produção têm as seguintes dimensões:

i) estrutura de input-output, isto é um conjunto de produtos e serviços ligados numa seqüência de atividades, que adicionam valor econômico;

ii) territorialidade, isto é a dispersão ou concentração espacial da produção e de redes de marketing, compreendendo empresas de diferentes tamanhos e tipos;

iii) estrutura de comando, isto é as relações de poder e autoridade que determinam como os recursos financeiros, materiais e humanos são alocados num fluxo dentro de uma cadeia. iv) ambientes institucionais, que podem ser locais, nacionais, regionais ou globais. 
Storper e Harrison (1991), por sua vez definem quatro tipos de estruturas de governança. O primeiro denominado all ring no core, onde não existe sistemática ou rotativamente uma firma líder em cada projeto, não existindo, em consequiência, uma hierarquia entre as empresas. Neste caso o acúmulo de capital social é que garantiria a governança dos distintos projetos de alocação de produção. Este tipo de estrutura de governança é o mesmo que existe nos distritos industriais clássicos. Os outros três tipos de estruturas de governança apresentam hierarquias de poder que decorrem da divisão social do trabalho entre as empresas: (i) podem se apresentar em um tipo de hierarquia entre firmas coordenadoras e subordinadas, bastante interdependente entre elas (core ring, with coordinating firm), que resulta em alguma hierarquia entre as empresas; (ii) entre uma empresa líder que é, entretanto, bastante independente das firmas subordinadas (core ring, with lead firm) e, portanto, a relação de hierarquia sobre as empresas é mais forte; ou, (iii) de uma integração vertical completa (all core, no ring) onde a hierarquia é completa devido à coincidência da propriedade de capital.

No que se refere às estratégias das cadeias produtivas, o enfoque tradicional da estratégia baseada no foco individual das empresas não é adequado para a mesma. Há necessidade de adoção de estratégias coletivas, que por sua vez está baseada no grau de simetria dos comportamentos dos integrantes. Essa simetria está diretamente relacionada com a governança estabelecida nos arranjos (PECK e JUTTNER, 2000).

Nesse contexto, Oliver (1990) aborda que as estratégias adotadas nos arranjos produtivos são dependentes das relações interorganizacionais, que por sua vez, dependem de fatores críticos, que podem atuar conjunta ou individualmente sobre estas relações. Esses fatores críticos podem ser assim identificados: necessidade, assimetria, reciprocidade, eficiência, estabilidade e legitimidade.

Segundo Bechtel e Jayaram (1997), o foco central da estratégia dos arranjos produtivos deve ser o de atender os requisitos do consumidor final da cadeia, da forma mais eficiente possível, atendendo requisitos de qualidade, minimização de perdas, desperdícios e custos, em prazos mínimos. Para isto devem ser utilizadas técnicas como BPR-Business Process Reengineering, TQM- Total Quality Management, análise de custos e pensamento sistêmico.

Para Lummus et al (1998), o gerenciamento do arranjo requer uma perspectiva estratégica para o atingimento da vantagem competitiva. Há necessidade de um processo de planejamento estratégico progressivamente desdobrado até atingir o nível da logística interna das empresas da cadeia. $\mathrm{O}$ autor propõe etapas a serem desenvolvidas no planejamento estratégico coletivo, quais sejam: desenvolvimento do plano estratégico da cadeia; priorizar as oportunidades de melhoria; definir os objetivos estratégicos e os indicadores de desempenho; desenvolver planos de trabalho detalhados; analisar periodicamente o desempenho da cadeia; executar os planos e monitorar o progresso dos resultados. Na visão de Fiegenbaum et al (1996), a formulação de estratégias deve considerar as referências internas (aspectos estratégicos internos) e as referências externas (foco na concorrência) e o tempo (evolução do desempenho).

Por outro lado, segundo Bresser (1988), as empresas das cadeias devem utilizar tanto estratégias competitivas como estratégias coletivas para gerenciar suas interdependências. $\mathrm{O}$ 
autor considera dois tipos de estratégias: estratégias competitivas (preço, marketing e inovação de produtos) e estratégias coletivas (estão na dependência dos mecanismos de coordenação utilizados). A questão fundamental para implantação efetiva de estratégias competitivas é analisar a compatibilidade entre as estratégias competitivas e os mecanismos de coordenação das estratégias coletivas. Quando as organizações utilizam simultâneamente os dois tipos de estratégias, estratégias competitivas em uma área de negócios e estratégias coletivas em outras, o potencial de atividades contraditórias e conflitos crescem porque a vantagem em uma área pode representar desvantagem em outra.

Nesse sentido, o mesmo autor acima citado chama atenção para os conflitos que podem surgir a partir do uso dos dois tipos de estratégias simultaneamente, quais sejam: competição no preço versus regulação na inovação; competição no preço versus inovação com diretorias inter-relacionadas; competição no preço versus marketing através de associações comerciais.

Pelo exposto, percebe-se que a formulação das estratégias das cadeias produtivas deve considerar tanto o posicionamento da mesma no mercado consumidor como as competências internas das empresas da cadeia.

No que se refere à competitividade, essa pode ser vista como uma medida de desempenho de uma firma individual ou de um produto. No entanto, este desempenho depende de relações sistêmicas, já que as estratégias empresariais podem modificar a competitividade global da cadeia (Farina, 1999; Ferraz et al. 1996).

$\mathrm{Na}$ ótica de Kennedy (1998) o principal indicador de competitividade, nessa contextualização, estaria ligado à participação de um produto ou firma individual em um determinado mercado. A utilização da participação do mercado (market share) como medida de competitividade é a contribuição mais difundida da economia neoclássica para os estudos de competitividade.

Ferraz et al. (1996), enfocam a competitividade como eficiência das ações estratégicas adotadas pelos agentes econômicos face às restrições do ambiente organizacional. Segundo essa ótica, existiria uma relação causal entre as estratégias adotadas pela firma e o seu desempenho eficiente, o que leva diretamente ao modelo teórico da organização industrial, qual seja, estrutura - conduta - desempenho. As concepções dos autores acima citados são complementares e importantes para o entendimento da análise da competitividade. Entretanto, suas abordagens negligenciam a capacidade de coordenação da cadeia produtiva em que as empresas desenvolvem suas estratégias.

Na visão de Farina (1999), para que as estratégias competitivas sejam bem sucedidas é necessária a existência de estruturas de coordenação apropriadas. A capacidade de articulação interna das cadeias representa um fator de competitividade, sendo que aquelas que possuem uma melhor articulação são mais eficientes em manter uma posição competitiva em mercados incertos e instáveis. Assim, para o estudo de competitividade em cadeias produtivas, é necessário focalizar o universo das relações existentes entre os diversos atores (MATUELLA et al., 1995).

Para Hansen (2004a), as estruturas de coordenação, bem como a confiança, o grau de negociação, a reputação dos atores, as relações interorganizacionais, entre outras, irão 
influenciar as estratégias das cadeias produtivas e de suas respectivas unidades produtivas. Nessa ótica, Coutinho e Ferraz (1995) propõem o entendimento de competitividade sistêmica, onde varáveis exógenas às empresas, também são responsáveis pelo desempenho empresarial.

Para entender a competitividade sistêmica, Hansen (2004a) cita que inúmeros trabalhos têm abordado essa temática. Entre os principais trabalhos destacam-se Porter (1990), Coutinho e Ferraz (1995), Casaroto Filho e Pires (1998) Lambert (1998) e Fleury e Fleury (2000). Esses trabalhos identificam a necessidade de consideração do nível mesoanalítico representado pelas relações interorganizacionais, quando se busca analisar a competitividade de cadeias produtivas. Segundo Hansen (2004a), a definição da abordagem meso-analítica de avaliação da competitividade sistêmica é essencial para a definição das variáveis a serem medidas, bem como a forma de medi-las. O mesmo autor enfatiza que a caracterização da cadeia produtiva, através de suas formas de governança e das estratégias relacionadas, constitui um aspecto básico para o desenvolvimento da medição de desempenho. A preocupação de entender e caracterizar o espaço meso-analítico através das inter-relações existentes entre os agentes é uma das funções dos estudos em cadeias produtivas (PEDROZO et.al., 1999).

Pires (2001) coloca que a meso-análise da competitividade busca preencher uma lacuna existente entre a microeconômica e a macroeconomia. $\mathrm{Na}$ visão desse autor, um enfoque meso-analítico permite responder as questões sobre o processo concorrencial e sobre as estratégias das empresas, bem como os processos produtivos entre os agentes. Segundo esse autor, o conceito de cadeia produtiva é importante para explicar e compreender as estruturas de produção, bem como criar um espaço meso-analítico.

Segundo Hansen (2004), a definição da abordagem meso-analítica de avaliação da competitividade sistêmica é essencial para a definição das variáveis a serem medidas, bem como a forma de medi-las. O mesmo autor enfatiza que a caracterização da cadeia produtiva, através de suas formas de governança e das estratégias relacionadas, constitui um aspecto básico para o desenvolvimento da medição de desempenho.

Hansen (2004), afirma que as variáveis governança e as estratégias cooperativas são fundamentais para a efetividade de um modelo de desempenho para cadeias produtivas. Nesse contexto, a dificuldade para operacionalizar em cadeias produtivas, um modelo de medição de desempenho desenvolvido para cadeias de suprimentos, conforme discutido anteriormente, é o mais comumente encontrado, é percebido em face da incapacidade desses em lidar com as variáveis governança, estratégias individuais e coletivas, fator externo de influência, multiplicidade das variáveis tecnológicas, sociais, econômicas e geográficas. Ocorre, também, a situação onde os diversos elos inter-relacionam-se, fazendo com que haja a necessidade de um sistema eficiente que acompanhe as atividades e mensure os resultados. Nesse contexto, a idéia de padronização de procedimentos e a tecnologia da informação ganham uma importância fundamental.

Hansen (2004), após um recente e aprofundado estudo sobre medição de desempenho, desenvolveu um modelo conceitual de medição de desempenho para cadeias produtivas. $\mathrm{O}$ modelo desenvolvido pelo autor originou-se, primeiramente, na identificação das variáveis de medição de desempenho em empresas individuais, que posteriormente foram adequadas à necessidade das cadeias produtivas, bem como na comparação do ambiente organizacional 
das empresas individuais e das cadeias produtivas. É incorporado ao modelo o conceito de meso-análise da competitividade ou competitividade sistêmica, que incorpora as relações inter-organizacionais e de outros fatores, que podem ser internos à cadeia, estruturais e externos a cadeia. Para que haja uma perfeita implementação do modelo, é fundamental a identificação das fontes necessárias dos dados que abastecerão o mesmo, bem como as características gerais dos bancos de dados das empresas e da cadeia como um todo. Para isso, é necessário que exista um eficiente sistema de informação gerencial que operacionalize as informações ao longo da cadeia produtiva.

O modelo proposto por Hansen (2004) tem uma aplicabilidade na medição de desempenho de um negócio em particular, envolvendo um produto/serviço, ou família de produtos bastante definidos, assim como o mercado a ser atendido. Essa limitação se dá face ao número de indicadores envolvidos, que tornariam impossível sua operacionalização. Dessa forma, uma cadeia produtiva com diversos negócios realizados não seria indicada para a aplicação do modelo de desempenho proposto pelo autor. Nesse mesmo contexto, o modelo foca-se na avaliação de mercados já atendidos pela cadeia produtiva, não servindo para análise de prospecção de novos mercados.

Sendo assim, a estrutura do modelo conceitual de medição de desempenho de cadeias produtivas desenvolvido por Hansen (2004) divide-se em dois estágios inter-relacionados, quais sejam: Estruturação do Modelo de Medição de Desempenho e Implementação do Modelo de Medição de Desempenho. A Estruturação do Modelo é composta de seis etapas, a saber:

Etapa 1 - Definição do segmento produtivo e do negócio a ser analisado

O passo inicial é determinar o segmento específico a ser analisado e as informações já disponíveis pelo mesmo. $\mathrm{O}$ autor coloca a importância dessa delimitação, face as diferentes características e condicionantes que podem estar envolvidos entre as diversas tipologias de cadeias produtivas (industriais, agronegócios, etc.). Depois de cumprida essa etapa, identificase o negócio a ser estudado. Esse passo consta de um estudo aprofundado sobre as características do mercado consumidor quanto às características socioculturais e geográficos, bem como a estrutura de coordenação presente na cadeia, entre outras.

Etapa 2 - Mapeamento preliminar e caracterização da cadeia produtiva a ser analisada Nessa etapa é caracterizada a idéia de cadeia produtiva genérica e específica, onde, a partir da identificação dos atores que compõem a cadeia produtiva genérica, podem-se subtrair os elos e suas especificidades, que irão compor a cadeia produtiva específica, o qual será avaliado seu desempenho. Como resultados relevantes dessa etapa visualizam-se a competitividade da cadeia no seu mercado de atuação, bem como a definição de quais os elementos serão importantes para serem medidos.

Etapa 3 - Análise Preliminar da Cadeia

Após a definição do segmento produtivo e do negócio a ser analisado, e a caracterização da cadeia produtiva a ser analisada, parte-se para a compreensão das relações causais existentes nos processos pertinentes à operacionalização da cadeia e de seus resultados competitivos alcançados. O foco central dessa etapa é estabelecer um modelo de desempenho da cadeia produtiva, que apresentem as possíveis relações causais entre as varias dimensões que afetam 
o desempenho competitivo. Feito isso, o próximo passo consiste em desdobrar essas dimensões, de forma a identificar os elementos a serem medidos nos diversos pontos da cadeia.

Etapa 4 - Definição das Medidas de Desempenho da Cadeia Produtiva

Depois de identificados os elementos a serem medidos, parte-se para a definição das medidas de desempenho. Para tanto, Hansen (2004) propõem as medidas de competitividade da cadeia e das empresas; medidas de resultados da cadeia, dos processos inter-empresariais, dos resultados das empresas, dos processos internos e dos fatores externos à cadeia.

Etapa 5 - Definição da Coleta de Dados e Estabelecimento do Banco de Dados da Medição de Desempenho.

Nessa etapa busca-se identificar e definir a coleta de dados, bem como estabelecer um banco de dados com o objetivo de possibilitar a avaliação de desempenho. No que se refere à coleta de dados, é de extrema importância à origem das fontes que irão abastecer o modelo. Essas fontes de coleta de dados devem ser fidedignas, senão corre-se o risco de comprometer a avaliação de desempenho da cadeia. Quanto ao banco de dados, esse necessita de um sistema informatizado eficiente para viabilizar a aplicação do modelo, haja vista a gama de informações necessárias para execução do processo de medição de desempenho.

Etapa 6 - Reavaliação Periódica frente a mudanças Estruturais

É sabido que o ambiente organizacional está constantemente sofrendo alterações em sua configuração. As mudanças tecnológicas, estratégicas, mercadológicas, bem como as alterações de coordenação e de gargalos ao longo da cadeia produtiva, fazem com que seja necessário realizar uma nova caracterização da cadeia e de seus indicadores de mensuração. Dessa forma, uma reavaliação periódica do modelo torna-se fundamental para que o mesmo esteja em sintonia com a realidade da cadeia produtiva.

Quanto ao processo de Implementação do Modelo de Medição de Desempenho de Cadeias Produtivas, Hansen (2004) estruturou o mesmo em quatro etapas, como pode ser visualizado na figura 1 . O processo de implementação inicia pela definição do tipo de governança da cadeia produtiva: hierárquica e quase-hierarquica; governança de redes; mercado. Conforme o tipo de governança existente na cadeia, existe uma forma de implementação do modelo. O próximo passo é implantar e difundir de forma sistemática a coleta de dados e de medição de desempenho. A variável relacionada à conscientização das empresas sobre o processo é de fundamental importância nessa etapa para o êxito da implantação do modelo. A partir dessa etapa, poderá ser analisada o desempenho da cadeia produtiva sob diversas óticas, podendo ser proposto ação de melhoria para os problemas identificados. A última etapa consiste em acompanhar continuamente os resultados alcançados, buscando com isso favorecer as ações gerenciais orientadas para a contínua melhoria de desempenho da mesma.

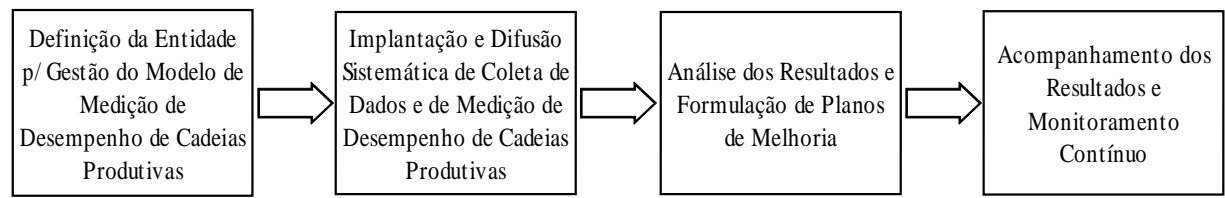


Figura 1: Processo de Implementação do Modelo de Medição de Desempenho de Cadeias Produtivas

Fonte: Hansen (2004)

Por fim, a partir da avaliação dos resultados obtidos com as ações gerencias implementadas, deve existir um processo de retroalimentação à etapa de estruturação do modelo que vise verificar e analisar as condições ambientais competitivas da cadeia produtiva, buscando com isso identificar novas propostas de melhoria de desempenho.

\section{ASPECTOS METODOLÓGICOS}

Tendo esse estudo uma função de caráter descritivo e exploratório de um fenômeno que não é suficientemente conhecido, no caso a forma de organização dos agentes dentro de uma cadeia produtiva e seu desempenho competitivo, a pesquisa caracteriza-se como exploratória (TRIPODI et al, 1975).

A presente pesquisa utilizará o estudo de caso, procedimento justificável pelo caráter exploratório da pesquisa (Tripodi et al, 1975). De acordo com Yin (1994), a opção de estudo de caso como estratégia de pesquisa se justifica quando o estudo focaliza o âmbito das decisões, isto é, tentam esclarecer o motivo pelo qual as decisões foram tomadas, como foram implementadas e quais os resultados encontrados. Será realizado um estudo multicasos, haja vista existirem casos diferenciados a serem estudados.

Quanto aos procedimentos técnicos, utilizou-se a pesquisa bibliográfica, em função da necessidade de um aprofundamento teórico sobre essa temática, bem como a aplicação de entrevistas estruturadas com agentes representativos (experts) da cadeia da carne bovina no Rio Grande do Sul, a fim de identificar o atual estado da arte. Foram entrevistados 10 produtores rurais, 02 gerentes de duas indústrias frigoríficas, 01 representande de uma Associação de Raças, 01 pesquisador da Empresa Brasileira de Pesquisa Agropecuária, e 01 professor da Universidade Federal do Rio Grande do Sul. Os dados utilizados foram de origem primária, quais sejam, as bibliografias consultadas e referenciadas no final do trabalho, bem como as entrevistas aplicadas nos agentes da referida cadeia.

Sendo assim, o artigo está estruturado em quatro partes, quais sejam: a) discussão sobre contextualização, governança, estratégias e competitividade dos relacionamentos interorganizacionais; b) caracterização dos relacionamentos interorganizacionais na bovinocultura de corte no RS; c) análise dos relacionamentos interorganizacionais na bovinocultura de corte do RS; d) considerações finais.

\section{CARACTERIZAÇÃO DOS RELACIONAMENTOS INTERORGANIZACIONAIS NA PECUÁRIA DO RS}

\subsection{A CADEIA PRODUTIVA}

Revista de Negócios, ISSN 1980-4431, Blumenau, v16, n.1, p.01 - 31, Janeiro/Março 2011. 
Na ótica de Bliska e Gonçalves (1998), a cadeia produtiva de carne bovina pode ser conceituada como um conjunto de componentes interativos, tais como diferentes sistemas produtivos, fornecedores de serviços e insumos, indústrias de processamento e transformação, distribuição e comercialização de produtos e subprodutos, e seus respectivos consumidores finais.

Segundo Malafaia et al. (2003), o processo tem seu início no setor de insumos, que representa as empresas de bens e serviços na área de nutrição, manejo, genética e sanidade. Após tem-se os setores produtivos, que reúnem as unidades produtoras que fornecem matérias-primas inicias para que outras empresas avancem no processo produtivo do bem final. Os frigoríficos são as empresas que são responsáveis pelo avanço do produto final em direção ao consumidor, transformando a matéria-prima em produto acabado e distribuindo para o segmento de varejo, que possui a missão de colocar o produto carne bovina à disposição do consumidor. Para que este sistema funcione perfeitamente, existem alguns elementos de apoio que são essenciais, pois são responsáveis pelo fluxo financeiro e de informações do sistema, conforme pode ser observado na figura 2.

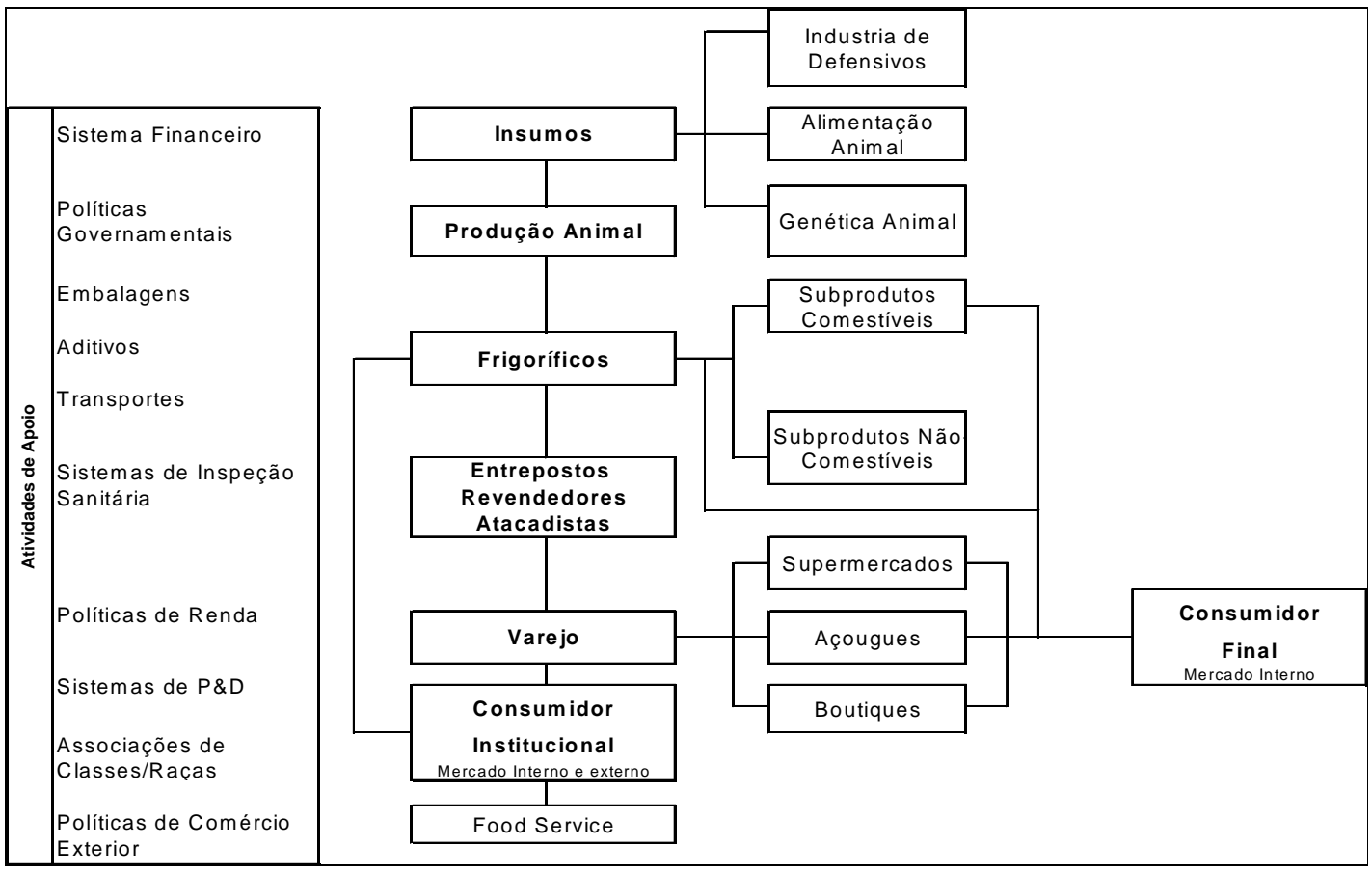

Figura 2: Estrutura da cadeia produtiva da carne bovina

Fonte: adaptado de IEL, SEBRAE, CNA, 2000

O setor de insumos fornece elementos necessários à eficiência da produção, como a base genética, alimentação, medicamentos, serviços, entre outros. O desempenho das unidades produtivas está diretamente correlacionado ao desenvolvimento da pesquisa científica e, em especial, aos trabalhos zootécnicos, biológicos, socioeconômicos e de difusão, realizados, principalmente, pelas Universidades, pela Empresa Brasileira de Pesquisa Agropecuária (EMBRAPA), pela Fundação Estadual de Pesquisa Agropecuária (FEPAGRO) e pela Empresa de Assistência Técnica e Extensão Rural (EMATER). 
Também se inserem nesse elo, as indústrias de produtos veterinários, que são responsáveis pela fabricação de vacinas, medicamentos e complementos nutricionais. Por último, também fazem parte deste elo, as empresas de sementes e forrageiras, de equipamentos, as fornecedoras de sêmem e embriões, bem como os serviços decorrentes da atuação desses agentes. O mercado de insumos agropecuários é dominado por um conjunto de empresas, na sua maioria multinacionais, que realizam extensão rural como estratégia de venda, ocupando dessa forma o espaço deixado pelo setor público (BLISKA E GONÇALVES, 1998).

O sistema de produção predominante é o extensivo, em regime de pastoreio, com pastagens naturais e /ou cultivadas, e possui três fases de produção distintas: cria; recria e engorda. A cria engloba os terneiros até o desmame ou até um ano de idade e os touros, vacas e novilhas em idade de produção. A recria inicia-se com um ano e termina quando as fêmeas atingirem o peso ideal de reprodução, e os machos atingem o desenvolvimento necessário para engorda. A engorda consiste na fase final de preparo para o abate. A idade média de abate gira em torno de 4,5 anos.

Ferreira (2003), cita que a taxa de desfrute de 17, $8 \%$ é considerada baixa quando comparada com os Estados Unidos (35\%) e Argentina (22\%). Existe no setor de produção uma forte sazonalidade do produto, em face da sensibilidade do pasto nativo a temperaturas baixas. Nesse sentido, existe o que se chama de safra (aumento da oferta), nos meses de primavera/verão e entressafra (escassez da oferta) nos meses de outono/inverno. Os principais problemas detectados no sistema de produção são os baixos índices de produtividade, a diversidade de raças, a deficiência na qualidade da mão-de-obra, os diferentes níveis de capitalização dos produtores e a falta de sanidade. No que se refere à produtividade, diversas tecnologias estão à disposição dos produtores, como a transferência de embriões, a inseminação artificial, entre outras.

Entretanto, o baixo nível de capitalização dos produtores e o custo elevado destas tecnologias, fazem com que praticamente seja inviabilizado o uso das mesmas. Novas práticas de manejo em termos alimentares e de maior eficiência na ocupação do espaço também são bastante difundidas. $\mathrm{O}$ confinamento apresenta-se como uma forma alternativa para resolver o problema de sazonalidade do produto. Entretanto, sua viabilidade econômica fica prejudicada diante do alto custo e da pequena diferença de preço que o produtor recebe. Muitos produtores optam pelo semiconfinamento, onde os animais são criados no campo, mas possuem sua alimentação suplementada com ração (BLISKA E GONÇALVES, 1998). Quanto à sanidade, é preciso uma maior conscientização por parte dos produtores de que o controle sanitário é primordial para aumentar as exportações do setor e, conseqüentemente, os preços pagos ao produtor (MALAFAIA et al., 2003). A comercialização dos produtos é intermediada, basicamente, por corretores de gado, que podem ser funcionários do frigorífico ou autônomos. Esses corretores compram ou intermedeiam o negócio para os frigoríficos. O preço é determinado pelo mercado, onde na safra o preço é baixo e na entressafra o preço aumenta (FERREIRA, 2003). 
Entre os frigoríficos existe uma heterogeneidade quanto às formas de gestão e ao desenvolvimento tecnológico. Encontra-se uma grande diversidade nos tamanho das plantas frigoríficas. Segundo Ferreira (2003), um fator que caracteriza a maioria dos frigoríficos é ociosidade dos mesmos, causada pela sazonalidade produtiva, bem como a antiguidade das plantas frigoríficas, que possuem um superdimensionamento da capacidade instalada, incompatíveis com a realidade atual. Os frigoríficos consideram a baixa qualidade da matériaprima e a sazonalidade do produto como um dos grandes problemas da cadeia, entretanto, não diferenciam o pagamento pela qualidade do produto, nem remuneram por rendimento de carcaça. Soma-se a estes problemas, os baixos níveis de higiene e sanidade e o abate clandestino que gera como conseqüências a falta de investimentos em inovações e inibem a entrada de novas empresas no Mercado. Ferreira (2003), aborda que além dos relacionamentos conflituosos com os produtores, os frigoríficos têm uma grande dificuldade de comercialização da carne. Observa-se que existe uma concentração maior no setor à jusante que faz com que seu poder de barganha prevaleça nas negociações, determinando o preço de venda. Segundo Bliska e Gonçalves (1998), a carne produzida destina-se ao mercado interno, que é menos exigente e à exportação, que tem um perfil mais exigente. A maioria da comercialização é in natura, sendo que a menor parte industrializada é exportada. A indústria voltada à exportação possui um grande diferencial tecnológico contrastando com os demais frigoríficos.

A distribuição de carne bovina é realizada por quatro canais genéricos: super/hipermercados, açougues, boutiques e feiras livres. Os fatores que diferenciam esses canais são os modelos de gestão e o posicionamento no mercado (IEL, CNA, SEBRAE, 2000). Os super/hipermercados detêm $80 \%$ da distribuição do produto, possuem alto poder de barganha, determinando preço e quantidade do produto. Exercem um papel necessário, qual seja agregar valor a um produto que chega em forma de carcaça e necessita ser transformado em cortes para serem comercializados ao consumidor. Os supermercados trabalham com uma margem de lucro de até $50 \%$, o que gera uma constante reclamação de produtores e frigoríficos, devido à margem desses últimos que é, em média, de 2\% (Ferreira, 2003).

O consumo de carne bovina é influenciado por vários fatores. Entre eles destacam-se as rendas, o preço da carne bovina e das carnes substitutas. Nesse contexto, o consumo de carne bovina aumentou na ultima década de $30 \mathrm{Kg} /$ per capita/ano para $36 \mathrm{Kg} /$ per capita/ano (IEL, CNA, SEBRAE, 2000).

No que se refere à coordenação da cadeia da carne bovina, esta praticamente não existe, uma vez que as relações entre os agentes se dão comumente via mercado. Segundo Jank (1996), a realidade brasileira é caracterizada pela presença de baixos níveis de integração contratual, onde a comercialização é um sistema defasado e ineficiente, repleto de oportunismo, assimetria de informações e falta de estabilidade de preços. Entretanto, quando se busca ofertar carnes de qualidade ("descomoditizadas"), com marca e certificação, essas formas de comercialização se alteram, passando a existir variadas formas de governança.

As estratégias utilizadas pela cadeia da carne bovina não se dão de forma coletiva, ou seja, os agentes estabelecem suas estratégias individualmente, com uma visão imediatista de curto prazo (Ferreira e Barcellos, 2004). Mesmo quando são estabelecidos arranjos produtivos, não se percebe um estabelecimento conjunto de estratégias de longo prazo, 
principalmente pelo ciclo de vida curto dos mesmos. As formas de avaliação de desempenho da cadeia, também se dão de forma individual, não ocorrendo de forma sistêmica. Mesmo quando são estabelecidos arranjos produtivos, as avaliações meso-analíticas são difíceis de se verificarem. Discute-se a seguir dois tipos de relações inteorganizacionais encontrados na bovinocultura de corte do RS.

\subsection{A GESTÃO DA CADEIA DE SUPRIMENTOS PELA INDÚSTRIA FRIGORÍFICA}

Segundo Lambert (2001), a Gestão da Cadeia de Suprimentos (GCS) pode ser entendida como a integração dos processos-chave do negócio desde o usuário final até os fornecedores iniciais de produtos, serviços e informações que agregam valor para os clientes e outros stakeholders. O caso em questão aborda a GCS pela industria frigorífica, a qual é uma organização que possui uma tradição de mais de trinta anos no mercado de carnes do RS e tem como principais atividades, a compra, o abate e a distribuição de carne bovina in natura. Possui uma estrutura industrial avançada em termos tecnológicos, onde grande parte das operações é automatizada. Sua capacidade de abate gira em torno de 10.000 animais / mês, entretanto, opera atualmente com uma capacidade ociosa, com um abate de 2.500 animais / mês.

Buscando se posicionar de forma estratégica, a empresa optou por diferenciar seus produtos no mercado. Para tanto, foi criada a marca best beef, cuja carne é oriunda de animais precoces. A empresa desossa, faz cortes especiais e embala a carne à vácuo. Devido à diferenciação, seu preço é superior em relação aos produtos comumente encontrados no mercado. Seu principal mercado é o pequeno varejo.

A empresa vem realizando esforços no sentido de consolidar a sua marca no mercado. Para isso, o estreitamento das relações tanto à montante como à jusante torna-se fundamental para o êxito da iniciativa. As principais iniciativas são o estabelecimento de relações mais próximas com as condições que criam valor ao produto (sistema de produção, abate, posicionamento no varejo). A figura 3 mostra como esta estruturada a cadeia de suprimentos da Indústria Frigorífica.

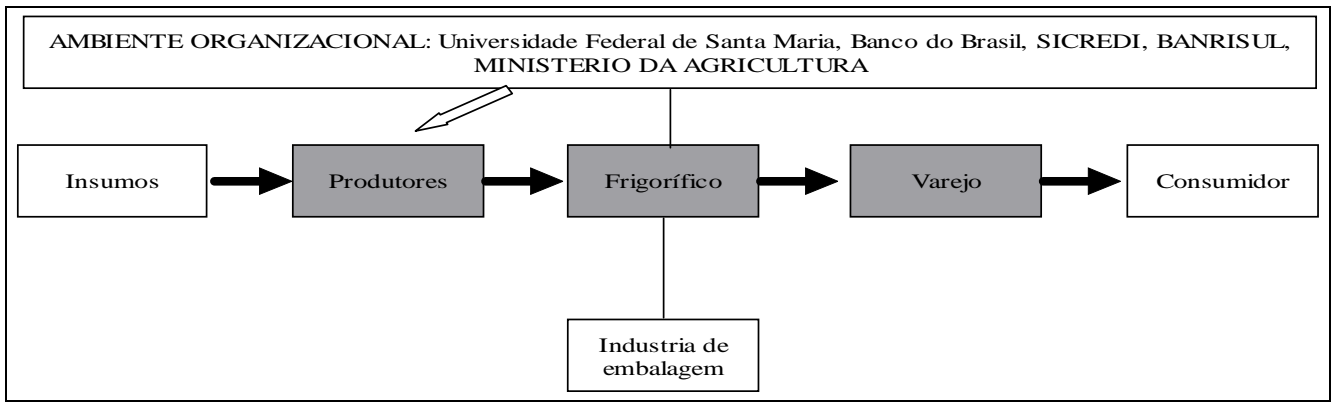

Figura 3. Cadeia de Suprimentos da Industria Frigorífica estudada.

Fonte: adaptado de Arbage, 2004.

Os membros - chave dessa cadeia de suprimentos são os produtores, a empresa focal e os varejistas. A indústria frigorífica para suprir-se de matéria-prima usa a figura do comprador especializado em $70 \%$ dos casos, sendo os outros $30 \%$ executados através do contato direto a 
partir do produtor. Esta é a forma de suprimento utilizada pela empresa para competir no mercado de carnes nobres.

A negociação com o varejo se dá principalmente com os pequenos lojistas, haja vista a dificuldade de negociar com as grandes redes, em face de exigência dos mesmos em barganhar preços. Como a empresa busca a diferenciar o seu produto, precisa ter preços atrativos. Esse é o principal entrave na relação. Existe uma única relação atualmente com uma grande rede varejista dos gaúchos. Não existem ações conjuntas, nem um planejamento conjunto nessa cadeia de suprimentos.

Percebe-se que a empresa possui uma visão de longo prazo da cadeia. Entretanto os movimentos ainda são bem incipientes. Os mecanismos de coordenação nesse arranjo limitam-se ao sistema de incentivos e medidas de orientação e assistência técnica. O Sistema de incentivo é baseado no pagamento diferenciado por qualidade do produto. O mecanismo de orientação e assistência técnica se dá mediante parceria com a Universidade Federal de Santa Maria, onde os produtores são orientados sobre sistemas de produção.

Existe uma relação de confiança, onde os produtores são fornecedores qualificados. Os contratos são informais. A estrutura de governança é uma estrutura híbrida, e muito próxima da governança de redes, sendo o diferencial a confiança entre as partes. Percebe-se que não existe um sistema de informação efetivo nessa cadeia de suprimentos. Não existe uma política de divisão de resultados nessa cadeia, o que possibilita o comportamento oportunístico dos agentes. Os riscos e lucros são de natureza específica dos agentes. Entretanto, a empresa busca premiar a qualidade e estabelecer uma relação de relativa confiança e reciprocidade.

\subsection{A ALIANÇA MERCADOLÓGICA: O PROGRAMA CARNE CERTIFICADA}

Outra forma de arranjo empresarial encontrada na cadeia produtiva da carne bovina no RS são as Alianças Mercadológicas, que são arranjos cooperativos entre duas ou mais empresas para melhorar as suas posições competitivas e seus desempenhos, através do compartilhamento dos recursos (Hitt et al., 2000).

A aliança em questão é denominada "Programa Carne Certificada", estabelecida entre um frigorífico, uma Associação Brasileira de Criadores de determinada raça e uma rede de supermercados gaúcha (Figura 4). Nessa Aliança, o objetivo é a produção de carne de alta qualidade "Premium" e a valorização da raça.

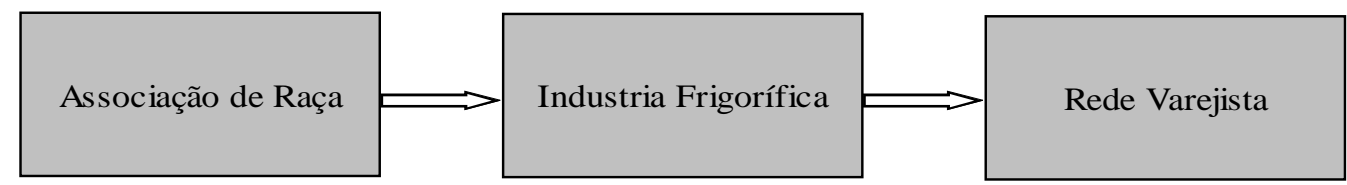

Figura 4. Estrutura da Aliança Mercadológica.

Fonte: Dados da pesquisa. 
Os objetivos dos agentes envolvidos nessa aliança são os seguintes: proporcionar aos produtores uma remuneração diferenciada, bem como possibilitar o acesso ao mercado interno e externo de um produto com a sua marca. Os objetivos da indústria são um pouco mais amplos, como, por exemplo, garantir a produção de um produto valorizado pelo mercado consumidor e reduzir a sazonalidade e a variabilidade da matéria-prima. No que se refere ao varejo, a aliança possibilitará possuir um produto premium na categoria de carne bovina, atendendo nichos de mercado crescentes com garantia de qualidade e regularidade.

As estratégias do programa são definidas em conjunto entre os participantes, onde a Associação de Raça exerce a função de articulação na Aliança, realizando a organização da oferta da matéria-prima junto aos produtores, fazendo as prospecções de demanda no mercado, acompanhando o processo de certificação no abate, contratando profissionais para atuarem em segmentos específicos, fazendo divulgação e promoção do programa.

O Frigorífico realiza pagamento diferenciado pela qualidade da carcaça e trabalha com programa de bonificação, que prevê benefícios financeiros aos produtores que planejam suas escalas de abate (denomina de compra qualificada, pagando $2 \%$ a mais de bonificação por cumprimento de metas e $\mathrm{R} \$ 0,5$ por $\mathrm{Kg}$ de carcaça). As características de diferenciação do produto: padrão do animal (idade, raça, acabamento de gordura), certificação de origem, fornecimento de informações relevantes ao consumidor (informações nutricionais, data de validade, etc.). $\mathrm{O}$ frigorífico além de remunerar o produtor de forma diferenciada, proporciona também o financiamento de reprodutores da raça para os produtores.

O varejo é o responsável por fazer com que o produto esteja à disposição do consumidor, colocando-o em posição de destaque na gôndola. Entretanto, a escala de abate em torno de 3.000 animais mês é considerada pequena, uma vez que atende apenas seis lojas da rede varejista. Nesse sentido, o varejo tem que se adequar à escala de abate do frigorífico.

\subsection{ANÁLISE DOS RELACIONAMENTOS INTERORGANIZACIONAIS NA PECUÁRIA DO RS}

Após caracterizar o ambiente organizacional da bovinocultura de corte do Rio Grande do Sul, onde se procurou descrever o cenário atual dos arranjos produtivos, bem como identificar e descrever as características dos seus elos, a seguir serão identificadas às formas de governança e as estratégias praticadas nesses arranjos.

Sendo assim, no que se refere à cadeia produtiva da carne bovina, percebe-se que a falta de coordenação é um sério problema dentro da mesma. Existe uma predominância de relações via mercado, o que faz com que a cadeia não consiga uma maior capacidade de adaptação às exigências dos diferentes segmentos de consumidores presentes nos mercados nacional e internacional. A incapacidade de interpretar os sinais do mercado e organizar-se no sentido de atendê-lo é um fator crucial para perda de competitividade em um mercado altamente acirrado. Para sobreviver e manter-se competitivo nesse mercado é necessário que haja uma estrutura eficiente que organize a produção. Baseado na visão de Storper e Harrison (1991), pode-se inferir que a cadeia da carne bovina no Rio Grande do Sul não possui uma estrutura de governança clara. Uma explicação para esse fato reside na falta de uma filosofia 
de cooperação vertical e horizontal entre os elos da referida cadeia, trazendo inúmeros prejuízos para o setor. Como no Rio Grande do Sul existe uma forte concentração da indústria frigorífica, fazendo com que o seu poder de negociação (exigências de padrões, determinação de preço) seja imposto nas transações com os produtores, pode-se caracterizar essa cadeia como buyer-driven commodity chains, ou seja, liderada pela indústria (Gereffi, 1994).

No que se refere às estratégias, a cultura organizacional dos agentes da cadeia, refletida na visão imediatista e oportunista, dificulta que se tenha um comportamento de cooperação, algo essencial em arranjos produtivos, fazendo com que não se consiga uma situação de vantagem competitiva. Como não existe uma relação de governança, as estratégias tornam-se exclusivamente individuais. Segundo Bresser (1988), a formulação das estratégias das cadeias produtivas deve considerar tanto o posicionamento da mesma no mercado consumidor, oriundo de uma estrutura de governança bem definida, como as competências internas das empresas da cadeia.

No caso da Gestão da Cadeia de Suprimentos da Indústria Frigorífica, nota-se que existe um objetivo bem definido, qual seja, produzir carne de qualidade oriunda de animais precoces, a fim de atender um nicho de mercado mais exigente. A estrutura de governança utilizada pode ser definida, segundo Storper e Harrison (1994), como core ring, with lead firm, ou seja, existe uma empresa líder que é bastante independente das firmas subordinadas e, portanto, a relação de hierarquia sobre os demais elos da cadeia é mais forte. Nessa cadeia de suprimentos não existem contratos formais, ficando as relações estabelecidas mediante a confiança entre as partes. Isto pode ser considerado um grande risco, haja vista ser comumente conhecida a falta de confiança e o comportamento oportunístico dos agentes da cadeia da carne (FERREIRA e BARCELLOS, 2004). Por outro lado, não existe uma política de divisão de resultados nessa cadeia, o que reforça a possibilidade de ocorrência de comportamento oportunístico dos agentes.

No que se refere às estratégias estabelecidas, Bresser (1988) enfatiza que as empresas das cadeias devem utilizar tanto estratégias competitivas como estratégias coletivas para gerenciar suas interdependências. Nesse sentido, percebe-se que a estratégia competitiva (principalmente, preço e inovação de produtos) é predominante na relação dessa cadeia de suprimentos. As estratégias coletivas são muito incipientes, limitando-se ao estabelecimento de um sistema de incentivo baseado no pagamento diferenciado por qualidade do produto e na orientação aos produtores sobre sistemas de produção.

Em linhas gerais, percebe-se que os principais resultados obtidos nessa cadeia de suprimentos são os seguintes: obtenção de um produto competitivo no mercado de carnes nobres; conquista de um preço premium pelo produto ofertado; projeção da marca no mercado nacional.

Na Aliança Mercadológica estudada, percebe-se, também, a existência de um objetivo bem definido, o de produzir um produto "descomoditizado", oriundo de animais jovens e com atributos de qualidade. Para tanto, a estrutura de governança utilizada na Aliança pode ser caracterizada, segundo Storper e Harrison (1991), como core ring, with coordinating firm, uma vez que o acordo de parceria foi proposto pela Associação de Raça. As relações comerciais entre os membros participantes da aliança não se verificam por meio de contratos 
formais. O que existe, apenas, é um termo de parceria estabelecendo as funções de cada agente na aliança, onde a exclusividade das transações é um dos pontos de referência.

As estratégias nessa aliança avançam um pouco mais na direção do coletivo, haja vista o envolvimento de todos os membros na formulação das mesmas. Entretanto, não parece claro à existência de um roteiro metodológico definido na elaboração das estratégias coletivas. Lummus et al (1998), considera fundamental para o sucesso de um arranjo uma perspectiva estratégica (auto-desenvolvimento do plano estratégico da cadeia; oportunidades de melhoria; a definição dos objetivos estratégicos e dos indicadores de desempenho; o desenvolvimento dos planos de trabalho detalhados; a análise periódica do desempenho da cadeia; a execução dos planos; a monitoração do progresso dos resultados) para o atendimento da vantagem competitiva. Nesse sentido, o que se percebe na aliança é uma preocupação maior com as estratégias competitivas que, segundo Bresser (1988), materializam-se em preço (busca de preço diferenciado), marketing (projeção da raça e da marca da aliança) e inovação de produtos/serviços (alta qualidade do produto ofertado; diferenciação da distribuição ao consumidor).

Por ser um arranjo recente, percebe-se uma limitação na capacidade de avaliar os resultados de desempenho. Entretanto, pode-se inferir que o produto esta conseguindo um desempenho satisfatório, considerando-se o aumento crescente do abate de animais no programa "carne certificada". O pagamento diferenciado aos produtores é outro ponto a ser destacado. Entretanto merece ser analisado mais profundamente, principalmente no que se refere à viabilidade do sistema de produção utilizado para produzir um produto com atributos diferenciáveis. A regularidade e a padronização do abastecimento pode ser visto como um resultado positivo da aliança. Isto faz com que a oferta de carne certificada e de qualidade percebida seja linear e constante ao mercado consumidor.

\section{CONSIDERAÇÕES FINAIS}

A visão isolada da unidade produtiva competitiva perde espaço para uma visão mais abrangente de grupos de empresas competitivas. Nesse sentido, o presente trabalho teve como objetivo delinear as relações interorganizacionais encontradas na bovinocultura de corte do RS. Para tanto, inicialmente, foram realizadas discussões teóricas sobre os conceitos de arranjos produtivos, governança, competitividade/estratégia. Num segundo momento, estes conceitos foram contextualizados bovinocultura de corte do RS.

Notou-se ao longo do trabalho que os relacionamentos interorganizacionais são importantes na medida em que possibilitam ofertar um produto diferenciado ao mercado e, conseqüentemente, sinalizam uma remuneração melhor para os participantes. Entretanto, o sucesso desses relacionamentos passa necessariamente pela mudança de postura dos agentes. Enquanto houver a predominância da visão isolada e imediatista dos agentes, o setor continuará deficitário em termos de competitividade.

Percebe-se que a falta de coordenação é um grande entrave para a cadeia produtiva da

carne bovina, fazendo com que seja impossível estabelecer estratégias coletivas e, conseqüentemente, ofertar um produto diferenciado. As relações via mercado possibilitam apenas a oferta de uma carne comoditizada, sem atributos de qualidade, direcionada a um 
mercado que possui uma alta elasticidade preço-demanda. O consumidor dessa carne considera o preço da carne como atributo principal na hora de comprar, sem se preocupar tanto com qualidade.

No que se refere à Cadeia de Suprimentos, percebe-se claramente a intenção da indústria frigorífica de descomoditizar a carne bovina, através da criação de uma marca própria, onde o produto ofertado é diferenciado pela qualidade, possuindo um preço mais elevado. Entretanto, a estrutura de governança adotada (muito próxima da governança via mercado) não parece ser a mais adequada, haja vista a necessidade da freqüência e da especificidade nas transações, bem como a presença do conhecido comportamento oportunístico dos agentes. A dificuldade de se estabelecer estratégias coletivas é um reflexo da estrutura de governança estabelecida nessa cadeia de suprimentos, onde a autonomia dos agentes predomina. No longo prazo, a estrutura de governança e as estratégias utilizadas pela industria frigorífica pode não oferecer sustentabilidade ao sistema, fazendo com que ocorra perda de competitividade.

Na Aliança Mercadológica, o produto é diferenciado pela certificação e qualidade, sendo direcionado para um publico que vê na qualidade da carne o principal atributo. Para esse público consumidor, a elasticidade preço-demanda é baixa, apesar de ainda predominar a falta de percepção dos consumidores quanto à carne de qualidade. No que se refere aos mecanismos de governança, percebe-se uma tentativa de se estabelecer uma relação de confiança, haja vista não existirem contratos formais de transações. Isso pode ser considerado um avanço, ao se tratar da pecuária de corte, historicamente cercada por imediatismos e comportamentos oportunísticos. Entretanto, há um risco grande de descontinuidade das operações. As estratégias deveriam abordar mais questões coletivas do que individuais, passando por uma sistematização do processo estratégico. Essa sistematização é fundamental para que ocorra sintonia nas operações, refletindo numa manutenção da competitividade no mercado de carnes nobres.

Nessa lógica, pode-se concluir que o estabelecimento de arranjos empresariais é fundamental para que se consiga manter a eficiência dos processos, pois minimiza as deficiências que as empresas possuem, fazendo com que o resultado final seja o aumento da competitividade coletiva. Como foi visto anteriormente, percebe-se que ainda é muito incipiente a ação de coordenação na bovinocultura de corte do RS, limitada a poucas iniciativas.

Sendo assim, espera-se com esse estudo ter contribuído com a discussão sobre a sustentabilidade da bovinocultura de corte no RS, chamando a atenção para a importância dos relacionamentos interorganizacionais. Quanto à discussão teórica, espera-se ter contribuído com as discussões sobre abordagens meso-analíticas, fundamentais para as análises da competitividade sistêmica.

\section{REFERÊNCIAS BIBLIOGRÁFICAS}

ARBAGE, A.P. Custos de transações e seu impacto na formação e gestão da cadeia de suprimentos: estudo de caso em estrutura de governança híbridas do SAG no Rio Grande do Sul. Tese de Doutorado. PPGA, UFRGS. 267 pg., 2004. 
BATALHA, M.O. As cadeias de produção agroindustriais: uma perspectiva para o estudo das inovações tecnológicas. In: Revista de Administração. São Paulo v.30, n.4, p.43 - 50, outubro/dezembro 1995.

BECHTEL, C., JAYARAM, J. (1997). SUPPLY CHAIN MANAGEMENT: a strategic perspective. The Internatiomal Journal of Logisitcs Management, v.8, n1.

BLISKA, F.M. DE MELlO;; GONÇALVES, J.R. Estudo da Cadeia Produtiva de Carne Bovina no Brasil. In: Cadeias Produtivas e Sistemas Naturais: Prospecção Tecnológica. Brasília: Embrapa-SPI/Embrapa-DPD, 1998.

COUTINHO, L., FERRAZ, J. Estudo da Competitividade da Industria Brasileira. Campinas, SP: Editora da Unicamp, 3.ed., 1995.

CASAROTO FILHO, N.; PIRES, L.H. Redes de Pequenas e Médias Empresas e Desenvolvimento Local. São Paulo: Atlas, SP, 1998.

FARINA, E.M.M.Q. Competitividade e Coordenação de Sistemas Agroindustriais: um ensaio conceitual. In: Revista Gestão \& Produção, vol.6, n.3, 1999.

FERRAZ, J.C., KUPFER. D, HAGUENAUER, L. Made in Brazil. Rio de Janeiro. Ed.Campus, 1996.

FERREIRA, G. Alianças Empresariais em Cadeias de Produção: Estrutura, Motivação e Estratégias na Produção de Carne Bovina. In: Anais do I Encontro de Estudos em Estratégias, Curitiba, PR, 2003.

FEREIRA, G.C.; BARCELlOS, M.D. Alianças Estratégicas em Cadeias Agroindustriais:Estudo de Caso na Cadeia da Carne Bovina. In: Anais da ENANPAD, Curitiba, PR, 2004.

FLEURY, A.; FLEURY, M.T. Estratégias Empresariais e Formação de Competências: um quebra-cabeça caleidoscópio da Industria Brasileira. São Paulo: Atlas, 2000.

HANSEN, P. Um Modelo Meso-Analítico de Medição de Desempenho Competitivo de Cadeia Produtivas. Tese de Doutorado. PPGEP/UFRGS, Porto Alegre, RS, 2004a.

HANSEN, P. Notas de Aula Análise Gerencial de Arranjos Empresariais, Porto Alegre, PPGEP/UFRGS, 2004b.

HITT, M. A.; DACIN, M.T.,LEVITAS, E.; ARREGLE, J.-L.; BORZA, A.. Partner selection in emerging and developed market contexts: Resource-based and organizational learning perspectives. Academy of Management Journal, 43: 449-467. 2000

IEL, SEBRAE.; CNA. Estudo sobre a eficiência econômica e competitividade da cadeia agroindustrial da pecuária de corte no Brasil. IEL, SEBRAE, CNA. Brasília, IEL, 2000.

JANK, M.S. Competitividade do Agribusiness Brasileiro: Discussão Teórica e Evidencias no Sistema Carnes. São Paulo. FEA/USP. 1996. Tese de Doutorado. 
KENNEDY, P.; HARRRISON, R.; KALITZANDOKANES, N. Analysing Agribusiness Competitiviness: The case of U.S. Sugar Industry. In: International Food and Agribusiness Management Reviw. v.1, n.2. 1998.

LAMBERT, D. Supply Chain Management: What does it envolve? Supply Chain \& Logistic Journal, fall 2001, v.4, Issue 4, Canadian Association of Supply Chain \& Logistics Management, Canada. 2001.

MALAFAIA, G.C.; CAMARGO, M.E.; PINTO, M.M.B. As Alianças Estratégicas como Alternativa para a competitividade da Cadeia Produtiva da Carne Bovina nos Campos de Cima da Serra/RS. In: I Congresso Brasileiro de Empreendedorismo - I CONEMPRE, Florianópolis, 2003.

MATTUELA, J.L.; FENSTERSIFER, J.; LANZER, E.A.. Competitividade em mercados agroindustriais integrados. In: Revista de Administração, São Paulo v.30, n.4, p.34 - 42. outubro/dezembro 1995.

MORVAN, Y. Filière deProduction. In: Fondaments déconomie Industrielle. Econômica, 1984.

NEVES, M.F.; JANK, M.S. Estratégias empresariais no Agribussines: Um referencial teórico e exemplos no MERCOSUL. IN: XVIII ENANPAD, Curitiba v.4, p.76 - 87. setembro de 1994.

GEREFFI, G. Capitalism, development and global commodity chains. In Sklair, Leslie (ed.): Capitalism and development. London : Routledge, 1994.

GEREFFI, G. Competitividade e redes na cadeia produtiva do vestuário na América do Norte. Revista latino-americana de estudos do trabalho, v. 4, n.6, 1998.

PECK, H.; JUTTNER, U.(2000). Strategy and Relationship: defining the interface in supply chain context. The Internatiomal Journal of Logisites Management, v.11, n2.

PEDROZO, Eugenio; HANSEN, Peter. (2001). Cluster, Filiere, Suply Chain, Redes Flexíveis: uma Analise Comparativa. In: Colóquio "As Relações Econômicas FrancoBrasileiras / Coloque "Lês Relations Industrielles Franco-Bresiliennes". Grenoble, France, Ecole Superieure dês Affaires / Université Pierre Mendes - France - Grenoble 2. 2930

PEDROZO, E.; MIELITZ NETO, C.G.; WAQUIL, P.O Sistema Integrado Agronegocial (SIAN): Uma Visão Interdisciplinar e Sistêmica. IN: II Workshop Brasileiro de Gestão de Negócios Agroalimentares. PENSA/FEA/USP, Ribeirão Preto, 1999.

PIRES, M.S. Construção de Modelo Endógeno, Sistêmico e Distintivo de Desenvolvimento Regional e sua Validação através da elaboração e da aplicação da Metodologia ao Caso Mercoeste. Tese de Doutorado. UFSC/PPGEPS, Florianópolis, SC, 2001.

PORTER, M. A Vantagem Competitiva das Nações. Rio de Janeiro: Campus, RJ, 1990. 
STORPER, M. ; HARRISON, B. Flexibility, hierarchy and regional development: The changing structure of industrial product systems and their forms of governance in the 1990s. Research Policy, 20, pp. 407-422, 1991.

ZILBERSZTANJ. D. Conceitos gerais, evolução e apresentação de sistemas agroindustriais. In: ZILBERSZTANJ. D. ; NEVES, M (org.), Economia e Gestão dos Negócios Agroalimentares, São Paulo: Pioneira, 2000. 